\title{
Produção de forragem e carga animal em pastagens de capim-elefante consorciadas com azevém, espécies de crescimento espontâneo e trevo- branco ou amendoim forrageiro
}

\author{
Clair Jorge Olivo ${ }^{1}$, Magnos Fernando Ziech², José Franscisco Both², Gilmar Roberto \\ Meinerz ${ }^{2}$, Denize Tyska ${ }^{2}$, Tiago Vendrame ${ }^{2}$

\footnotetext{
${ }^{1}$ Departamento de Zootecnia, Universidade Federal de Santa Maria Campus - Camobi, CEP: 97105-900, Santa Maria - RS - Brasil

2 Curso de Zootecnia da UFSM, Santa Maria - RS - Brasil.
}

RESUMO - Avaliaram-se a dinâmica e o desempenho de uma pastagem em dois sistemas forrageiros: SF1 - capim-elefante (CE) + azevém (AZ) + trevo-branco (TB) + espécies de crescimento espontâneo (ECE); e SF2 - capim-elefante + azevém + amendoim forrageiro (AF) + ECE. Utilizaram-se quatro piquetes de 0,25 ha com o capim-elefante estabelecido em linhas afastadas a cada $4 \mathrm{~m}$, em delineamento de blocos ao acaso, com dois sistemas forrageiros e duas repetições (piquetes). As pastagens foram adubadas com N- $\mathrm{P}_{2} \mathrm{O}_{5}-\mathrm{K}_{2} \mathrm{O}$ (50-40-40 kg/ha/ano, respectivamente). Durante o período experimental, foram realizados nove pastejos (326 dias no SF1 e 336 dias no SF2). Foram usadas para avaliação vacas em lactação da raça Holandesa recebendo suplementação com concentrado (3,5 kg/dia). Foram colhidas no pré-pastejo amostras representativas da massa de forragem da pastagem nos piquetes. Os valores médios de matéria seca da massa de forragem da pastagem, de lâminas foliares do capim-elefante, do azevém e de leguminosas foram de 3,76; 0,85 e 0,26 t/ha no SF1 e 4,60; 0,99 e 0,19 t/ha no SF2, respectivamente. Considerando os períodos hibernal e estival, os valores médios da carga animal foram de 2,22 e 2,29 e de 3,14 e 3,01 UA/ha, respectivamente, para o SF1 e o SF2. Os resultados foram similares entre os sistemas forrageiros. Como o capim-elefante predomina nesses sistemas, a utilização do azevém, das leguminosas e das espécies de crescimento espontâneo permitiu manter a massa de forragem uniforme no decorrer dos pastejos. Os resultados sugerem que o capim-elefante pode ser utilizado segundo as misturas forrageiras propostas.

Palavras-chave: Arachis pintoi, pastagens consorciadas, Pennisetum purpureum, Trifolium repens

\section{Forage production an stocking rate on elephantgrass pastures mixed with ryegrass, spontaneous growth species and white clover or forage peanut}

\begin{abstract}
The objective of this work was to evaluate the dynamic and animal performance in two pasture-based systems (PS), with elephantgrass (EG) + ryegrass (RG) + white clover (WC) + spontaneous growing species (SGS) for PS1; and $\mathrm{EG}+\mathrm{RG}+$ forage peanut (FP) + SGS for PS2. Four paddocks, each one with 0.25 ha, were used in the evaluation. EG was established in lines with a distance of $4 \mathrm{~m}$ between each one of them. The experimental design was randomized blocks with two replicates (paddocks). Pastures were fertilized with $50-40-40 \mathrm{~kg} / \mathrm{ha}$ of $\mathrm{N}-\mathrm{P}-\mathrm{K}$, respectively. Nine grazing cycles were performed during the experimental period (326 days in PS1 and 336 in PS2). Holstein cows receiving $3.5 \mathrm{~kg} /$ daily complementary concentrate feed were used in the evaluation. Pregraze samples representing the average paddock herbage mass were collected. The mean values of dry matter for pregraze herbage mass, EG leaf lamina and legumes were 3.76, 0.85 and 0.26 t/ha in PS1 and 4.60; 0.99 and 0.19 t/ha in PS2, respectively. Considering the hibernal and estival periods, the average values of carrying capacity were 2.22 and 2.29 and 3.14 and $3.01 \mathrm{UA} /$ ha for PS1 and PS2, respectively. Similar results were observed for the pasture systems. The use of ryegrass, legumes and the spontaneous growing species allowed the forage mass to be uniform during the grazing at these EG-based systems. The results suggest that EG could be used under the mixed pastures proposed.
\end{abstract}

Key Words: Arachis pintoi, mixed pastures, Pennisetum purpureum, Trifolium repens

\section{Introdução}

O capim-elefante (Pennisetum purpureum Schum.) é uma forrageira importante nas propriedades leiteiras, especialmente por sua perenidade e por apresentar elevada produção de massa de forragem; seu uso tem se intensificado sob a forma de pastagem, implicando na melhoria do volumoso ofertado e na redução de mão-de-obra em comparação à sua utilização como capineira (Faria, 1999). O clima frio e úmido da região Sul impõe restrições ao cultivo 
do capim-elefante, o que não ocorre na maioria das regiões do Brasil onde essa gramínea é tradicionalmente cultivada. O Rio Grande do Sul caracteriza-se por invernos rigorosos, com geadas e temperaturas abaixo de zero, que limitam o desenvolvimento das espécies tropicais por quatro a cinco meses do ano.

Entre as espécies de leguminosas indicadas para o consórcio com gramíneas de clima temperado, o trevobranco é uma boa opção para compor misturas forrageiras. No entanto, em condições de clima subtropical, a persistência desta espécie é comprometida pela ocorrência de verões quentes e secos (Scheffer-Basso et al., 2002). Entretanto, segundo Paim \& Riboldi (1994), mesmo em pastejo intenso ou com cortes freqüentes, ocorre a produção de sementes dessa espécie, em virtude da presença de estolões no nível do solo e do tempo de maturação das sementes, que, com o surgimento do botão floral, em períodos quentes, varia de 20 a 30 dias, garantindo a ressemeadura natural.

Por outro lado, para o clima tropical, o amendoim forrageiro tem se mostrado uma alternativa viável na produção forrageira, pois, quando usado na formação de pastagens consorciadas, suporta taxas de lotação de até 4 novilhos/ha, com ganhos de peso vivo superiores a $550 \mathrm{~g} /$ animal/dia e $500 \mathrm{~kg}$ de peso vivo/ha/ano (Santana et al., 1998).

A principal expectativa do uso de leguminosas é a melhoria da produção animal em relação à pastagem de gramínea exclusiva submetida ou não à adubação nitrogenada e a redução de custos (Assmann et al., 2004). Este benefício é reportado como efeito da participação direta da leguminosa melhorando e diversificando a dieta do animal e também do aumento da disponibilidade de forragem pelo aporte de nitrogênio ao sistema, por meio de sua reciclagem e transferência para a gramínea acompanhante (Pereira, 2001; Santos et al., 2002).

Assim, estudou-se o desempenho de pastagens de capim-elefante, azevém e trevo-branco ou amendoim forrageiro estabelecidas nas entrelinhas e manejadas com bovinos leiteiros.

\section{Material e Métodos}

Este trabalho foi conduzido no Laboratório de Bovinocultura de Leite, pertencente ao Departamento de Zootecnia da UFSM, situado na Depressão Central do Rio Grande do Sul, a $29^{\circ} 43^{\prime}$ de latitude Sul e 5342' de longitude Oeste, com clima Subtropical Úmido (Moreno, 1961). As médias anuais de precipitação ficam entre 1.300 e $1.800 \mathrm{~mm}$ e de temperatura em torno de $19,4^{\circ} \mathrm{C}$. O solo é classificado como Argissolo Vermelho distrófico arênico (Embrapa, 1999).

A área utilizada (1,0 ha) foi dividida em quatro piquetes (0,25 ha cada), todos com o capim-elefante (Pennisetum purpureum Schum.) cv. Merckeron Pinda como base do sistema forrageiro. O capim-elefante foi estabelecido em linhas afastadas $4 \mathrm{~m}$ entre os anos de 2002 e 2003. Em dezembro de 2004, nas entrelinhas, o amendoim forrageiro (Arachis pintoi Krapov. \& Greg.), cv. Amarillo, foi implantado em metade da área (dois piquetes) em densidade de semeadura de $12 \mathrm{~kg}$ de sementes/ha. Na outra metade, em junho de 2005, mediante escarificação do solo, foram estabelecidos o trevo-branco (Trifolium repens L.), cv. Yi, em densidade de $4 \mathrm{~kg}$ de sementes/ha, e o azevém (Lolium multiflorum Lam.), cv. Comum (40 kg de sementes/ha). Na área estabelecida com amendoim forrageiro, a implantação do azevém (40 kg de sementes/ha) foi realizada por sobresemeadura. No período estival, permitiu-se nas entrelinhas o desenvolvimento de espécies de crescimento espontâneo. No estabelecimento dos pastos, não foi utilizado herbicida.

Para adubação foram utilizados $\mathrm{P}_{2} \mathrm{O}_{5}(40 \mathrm{~kg} / \mathrm{ha} / \mathrm{ano})$ e $\mathrm{K}_{2} \mathrm{O}$ (40 kg/ha/ano), conforme recomendação de análise de solo para leguminosas perenes usadas (Manual de adubação e calagem para os Estados do Rio Grande do Sul e Santa Catarina, 2004). No período, foram utilizados $50 \mathrm{~kg} / \mathrm{ha} /$ ano de nitrogênio, sob a forma de uréia, divididos em duas aplicações.

Um dos sistemas forrageiros foi composto de capimelefante + trevo-branco + azevém + espécies de crescimento espontâneo e outro, de capim-elefante + amendoim forrageiro + azevém + espécies de crescimento espontâneo. A área correspondente ao capim-elefante foi de $25 \%$ e o restante, pelas espécies presentes nas entrelinhas.

Utilizaram-se vacas em lactação da raça Holandesa, com $530 \pm 30,5$ kg e produção de $17 \pm 2,31 /$ dia, recebendo complementação alimentar diária de 3,5 kg de concentrado com $20 \%$ de proteína bruta (durante todo o ano agrícola) mais 3,5 kg de MS de silagem de milho (apenas no período hibernal), fornecidos após as ordenhas (manhã e tarde). As vacas permaneceram nas pastagens das $9 \mathrm{~h}$ às $16 \mathrm{~h} \mathrm{e}$ das $18 \mathrm{~h}$ às $7 \mathrm{~h}$, com acesso à sombra, água e sal mineral.

Durante o período hibernal, o critério de utilização da pastagem teve como base as espécies estabelecidas na entrelinha. O pastejo foi iniciado quando as espécies apresentavam, aproximadamente, $20 \mathrm{~cm}$ de altura. No período estival, a pastagem foi utilizada quando o capim-elefante apresentava 100 a $120 \mathrm{~cm}$ de altura.

Antecedendo a entrada dos animais, foi calculada a massa de forragem, estimada mediante a técnica de dupla 
amostragem (Wilm et al., 1944), com cinco cortes na entrelinha (rente ao solo) e 20 estimativas visuais, repetindo-se o processo na linha (corte a $50 \mathrm{~cm}$ do solo). As amostras foram pesadas e homogeneizadas, retirando-se uma subamostra para estimativa das composições botânica e estrutural das pastagens. As subamostras foram posteriormente encaminhadas para estufa para determinação da MS. No capimelefante, após a saída dos animais, fez-se a dupla amostragem pelo mesmo procedimento da avaliação de pré-pastejo.

Para determinar a quantidade de animais a ser utilizada (carga animal), procurou-se manter a oferta de forragem entre 8 e $10 \mathrm{~kg}$ de MS/100 kg de peso vivo para a entrelinha e $4 \mathrm{~kg}$ de MS/100 kg de peso vivo para a biomassa de lâminas foliares de capim-elefante, baseando-se na massa de forragem inicial das espécies presentes na entrelinha e do capim elefante, respectivamente.

O delineamento experimental foi o de blocos ao acaso (ano de implantação do capim-elefante), com dois sistemas forrageiros, duas repetições de área (piquetes) e em parcelas subdivididas no tempo (pastejos). Os dados foram submetidos às análises de variância e de correlação a 5\% de significância. As variáveis que apresentaram interação sistema forrageiro $\times$ pastejo foram submetidas à análise de regressão polinomial. As análises foram efetuadas com auxílio do pacote estatístico SAS versão 6.12 (1997). O modelo estatístico referente à análise das variáveis estudadas da pastagem foi representado por:

$$
Y i j k=m+T i+B j(T i)+P k+T i P k+e i j k .
$$

em que Yijk = variáveis dependentes; $\mathrm{i}$ = índice de tratamentos (pastagens); $\mathrm{j}=$ índice de repetições; $\mathrm{k}$ = índice de pastejos; $\mathrm{m}=$ média de todas as observações; $\mathrm{Ti}=$ efeito dos sistemas forrageiros; $\mathrm{Bj}$ = efeito dos blocos/piquetes; $\mathrm{Bj}(\mathrm{Ti})=$ efeito de piquete dentro de tratamento (erro a); $\mathrm{Pk}=$ efeito dos pastejos; TiPk = interação pastagens $\times$ pastejos; e eijk = erro experimental residual (erro b).

\section{Resultados e Discussão}

A avaliação em pastejo foi conduzida entre o período de 24/5/2005 a 2/5/2006, perfazendo um total de 343 dias: 24/5/2005 a 25/4/2006 (336 dias) no sistema consorciado com AF e de 11/6/2005 a 2/5/2006 (326 dias), para o sistema contendo trevo-branco. No período, foram realizados nove ciclos de pastejo por sistema forrageiro, quatro no período hibernal (julho a outubro) e cinco no estival (dezembro a maio). O tempo de ocupação variou de 1 a 2 dias e o de descanso, de 35 a 38 dias para os períodos hibernal e estival, respectivamente.

Considerando os tempos de ocupação e descanso, somado ao manejo utilizado, os ciclos de pastejo são adequados (Fonseca et al., 1998; Aroeira et al., 1999; Deresz et al., 2001 b). Períodos curtos de ocupação de até três dias e de descanso próximo a 30 dias para espécies tropicais estão associados ao melhor valor nutritivo da forragem (Soares et al., 2004) e à maior produção de leite (Fonseca et al., 1998).

A massa de forragem total foi similar entre os sistemas forrageiros na maioria dos pastejos (Tabela 1). Houve diferença $(\mathrm{P}<0,05)$ na média dos sistemas, com maior valor na pastagem com amendoim forrageiro. Esse resultado deve-se à maior participação da massa de forragem da entrelinha no final do período estival e à maior participação de colmos e material morto do capim-elefante. No entanto, a biomassa de lâminas foliares verdes do capimelefante de pré-pastejo não diferiu ( $\mathrm{P}>0,05)$ entre os sistemas, indicando que houve similaridade na fração mais importante do principal componente da pastagem, condição evidenciada pelo baixo coeficiente de variação encontrado para essa variável.

A biomassa de lâminas foliares verdes do capim-elefante no pós-pastejo, utilizada para monitorar o manejo dessa forrageira, também não apresentou diferença $(\mathrm{P}>0,05)$, tanto nos pastejos quanto na média dos sistemas forrageiros. Os valores percentuais dessa variável situaram-se entre 18,97 e 11,71 em janeiro e abril, respectivamente, e foram inferiores aos recomendados por Hillesheim (1995), que indica resíduo de lâmina foliar próximo a 25\% para esta forrageira no período estival.

A participação do capim-elefante, que ocupou $25 \%$ da área, foi de aproximadamente 72,19 e 75,22\% para o SF1 e SF2. O valor médio da massa de forragem, próximo a $4 \mathrm{t} / \mathrm{ha}$, é semelhante à disponibilidade encontrada por Restle et al. (2002), de 3,6 t/ha, no Rio Grande do Sul, em sistema forrageiro com cv. Taiwan A-146 estabelecido na forma exclusiva, adubado com $500 \mathrm{~kg} / \mathrm{h}$ de nitrogênio, avaliado entre dezembro e abril (corte rente ao solo). Valores mais elevados, de 5,5 no início e 4,4 t/ha no final do período das águas, foram observados por Lima et al. (2004), em São Paulo, trabalhando com o cv. Guaçu adubado com $250 \mathrm{~kg} / \mathrm{ha}$ de nitrogênio, avaliado no período de dezembro a abril em quatro ciclos de pastejo.Os maiores valores de colmo e material morto estão associados à maior massa de forragem do capim-elefante.

Verificou-se efeito cúbico com início descendente, tanto para a massa de forragem quanto para a biomassa de lâminas foliares verdes do capim-elefante, em ambos os sistemas forrageiros (Figura 1). Ao contrário do esperado (menor produção de forragem dessa espécie no período hibernal), os valores obtidos em média 67,32 e 78,10\% da produção total de massa de forragem desse período para os 
A $\mathrm{SF} 1=\mathrm{CE}+\mathrm{AZ}+\mathrm{TB}+\mathrm{ECE}$

- MFCE $y=3,87884-0,0460002 x+0,0003047 \times 2-0,000000525 ; R^{2}=0,76$ $\triangle B L F V E y=2,19187-0,0411942+0,0002628 \times 2-0,000000524 \times 3 ; R^{2}=0,93$ XMFEL $y=-1,22343+0,0412531 x+0,00018762-0,000000254 \times 3 ; R^{2}=0,72$ - TB $y=-0,074223+0,0004745 x+0,00000006 \times 2 ; R^{2}=0,74$

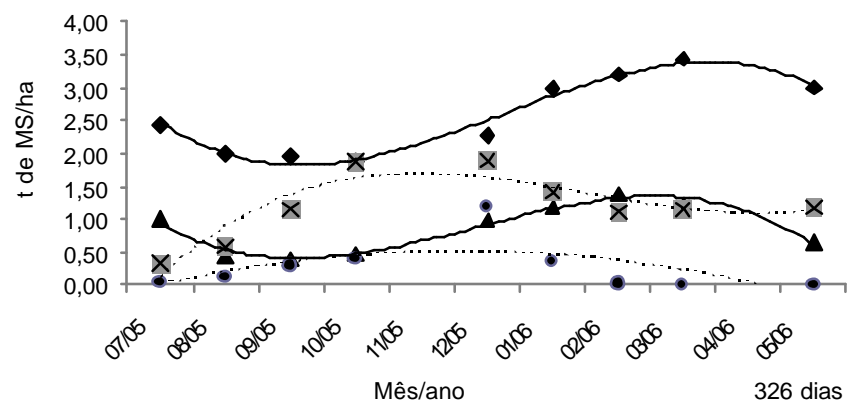

B

$\mathrm{SF} 2=\mathrm{CE}+\mathrm{AZ}+\mathrm{AF}+\mathrm{ECE}$

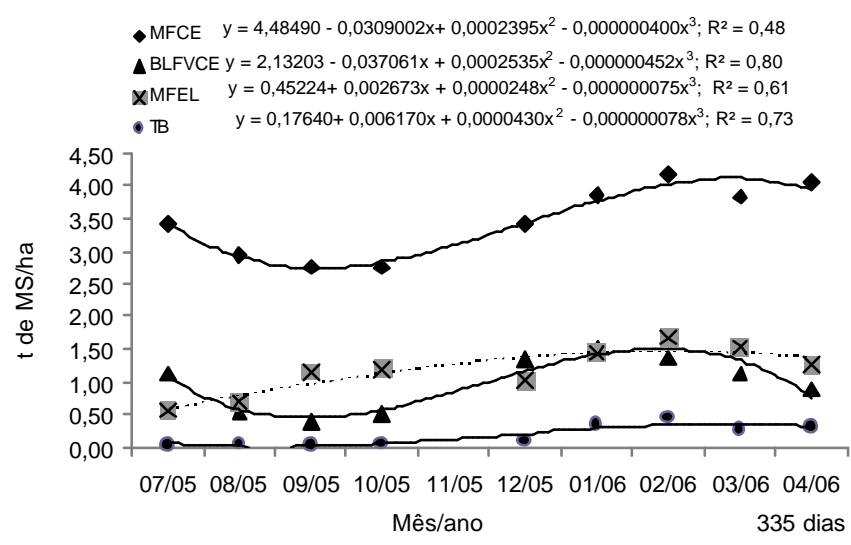

Figura 1 - Massa de forragem de capim-elefante (MFCE), biomassa de lâminas foliares verdes de capim-elefante (BLFVCE), massa de forragem da entrelinha (MFEL) e diferentes leguminosas, em dois sistemas forrageiros (SF).

CE - capim-elefante; AZ - azevém; TB - trevo-branco; AFamendoim forrageiro; ECE - espécies de crescimento espontâneo.

SF1 e SF2, respectivamente, são altos. Sobczak et al. (2005) verificaram participação de $76,29 \%$ do capim-elefante em pastagem consorciada com aveia mas com menor espaçamento entre linhas.

A massa de forragem presente na entrelinha (Tabela 1) foi similar entre os sistemas na maioria dos pastejo, a exceção dos períodos em que as leguminosas apresentaram maior participação, do trevo-branco (em outubro e dezembro) e do amendoim (fevereiro e abril). Considerando as médias dos sistemas, não houve diferença $(\mathrm{P}>0,05)$ entre elas. Nos dois sistemas constituídos (Figura 1), a consorciação com leguminosas e azevém, especialmente, permitiu maior equilíbrio na forragem ofertada aos animais. Enquanto o capim-elefante apresenta produção descendente no período hibernal, a participação de espécies presentes na entrelinha apresenta comportamento ascendente, mais intenso no SF1. No sistema com amendoim forrageiro, a distribuição de forragem melhorou no decorrer do tempo, ocasionando maior equilíbrio no início do outono. Trabalhos conduzidos com capim-elefante em regiões de clima subtropical estabelecido na forma exclusiva comprovam declínio acentuado de produção de forragem já em meados do outono (Restle et al., 2002; Lima et al., 2004). Essa estabilidade na disponibilidade da massa de forragem no decorrer do ano proporciona maior equilíbrio no manejo da pastagem e dos animais, mesmo em épocas tradicionais de escassez de pastagens.

A participação do azevém, avaliada pela massa de forragem de lâminas foliares e colmos, foi similar $(\mathrm{P}>0,05)$ entre os sistemas forrageiros (Tabela 1). Essa contribuição é baixa, uma vez que essa forrageira estava presente em $75 \%$ da área. Normalmente pesquisas conduzidas com azevém, tanto na forma exclusiva como em misturas com outras espécies, submetido a maiores níveis de adubação, apresentam valores mais elevados de massa de forragem (Marchesan et al., 2002). No entanto, apesar dessa baixa produção, a maior participação do azevém ocorreu justamente quando houve a menor contribuição de lâminas foliares de capim-elefante, o que comprova sua importância para manutenção da oferta e da qualidade de forragem nos sistemas em análise.

Mesmo com as diferenças de participação entre as leguminosas no decorrer do ano agrícola, na média não se detectou diferença $(P>0,05)$ na massa de forragem das leguminosas (Tabela 1). A participação média do trevobranco e do amendoim na massa de forragem foi de 6,11 e $3,86 \%$ e, considerando somente a entrelinha, os valores foram de 17,84 e 14,67\%, respectivamente. Para o trevobranco (SF1), verificou-se comportamento cúbico dos dados, com início ascendente e maior participação justamente quando o capim-elefante apresentava baixa disponibilidade de lâminas foliares (Figura 1A). Comportamento similar, com ápice de desenvolvimento entre outubro e dezembro e produção de MS média de nove cortes de $1,04 \mathrm{t} / \mathrm{ha}$, foi obtida por Scheffer-Basso et al. (2005) em trabalho conduzido no Rio Grande do Sul com trevo-branco estabelecido na forma exclusiva. Para o amendoim forrageiro, no SF2, verificou-se o mesmo efeito, com ápice de desenvolvimento em fevereiro. Comparativamente, essa leguminosa teve participação mais constante no decorrer dos pastejos (Figura 1B). A manutenção da massa de forragem em março 


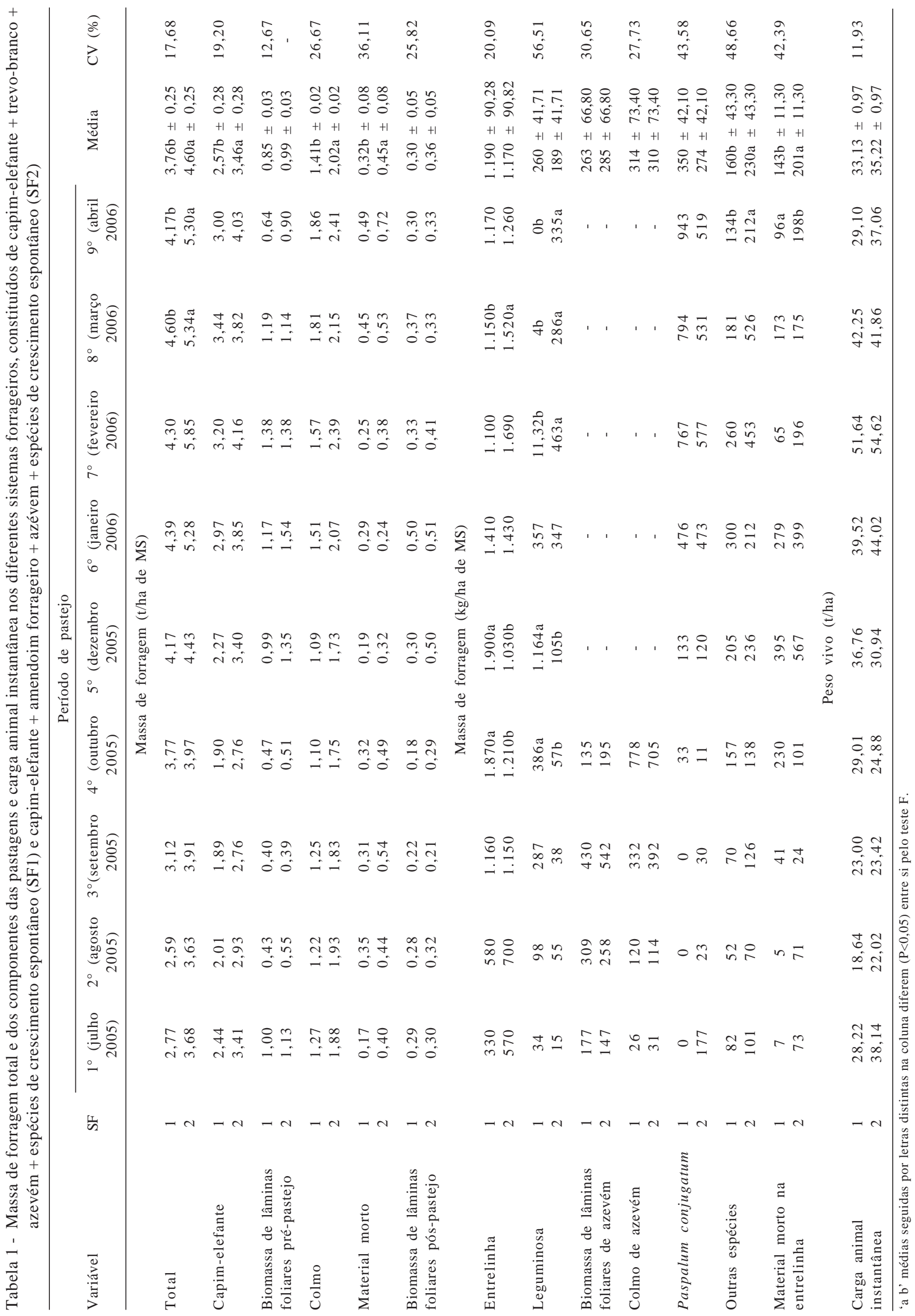


e abril indica que essa leguminosa pode ser importante na manutenção do valor nutritivo da forragem no outono (Santos et al., 2002), especialmente em regiões subtropicais, que tradicionalmente apresentam problemas típicos de escassez de forragem nesse período (Restle et al., 2002). Valores elevados de massa de forragem dessa leguminosa têm sido verificados em diferentes regiões do Brasil, comprovando elevado grau de adaptação a diferentes sistemas forrageiros (Andrade \& Valentim, 1999). Em consorciação de amendoim forrageiro cv. AC 01 e capim-massai (Panicum maximum x $P$. infestum), com ofertas de 9,0;14,5 e 18,4\% do peso vivo, sob pastejo rotacionado com 33 dias de descanso, Andrade et al. (2006) verificaram participação de 25,$5 ; 10,6$ e $6,4 \%$ na pastagem e constataram aumento na participação da leguminosa no decorrer da avaliação. Esse comportamento provavelmente ocorreu no SF2, pois esse foi o primeiro ano de avaliação.

A presença de outras espécies, em maioria de ciclo estival, confirmam a elevação dos valores de massa de forragem nesse período. $\mathrm{O}$ maior valor $(\mathrm{P}<0,05)$ encontrado no SF2 deve-se ao Paspalum conjugatum, cuja maior participação provavelmente está relacionada à forma de estabelecimento do azevém, feita com distribuição a lanço nas entrelinhas. No SF1 fez-se a escarificação do solo para o plantio do azevém e do trevo-branco, o que reduziu a presença de Paspalum na composição da pastagem. Outras espécies de crescimento espontâneo, encontradas na entrelinha, mas com menor contribuição que o Paspalum, como papuã (Urochloa plantagínea), milhã (Digitaria sanguinalis), guanxuma (Sida santaremnensis) e erva-debicho (Polygonum persicaria), apresentaram diferença $(\mathrm{P}<0,05)$ na média anual, com valores mais baixos no sistema forrageiro com trevo-branco, provavelmente em razão da maior contribuição dessa leguminosa na primavera, o que inibiu o desenvolvimento inicial dessas espécies. Estudos conduzidos no Rio Grande do Sul confirmam que gramíneas de crescimento espontâneo como o milhã e o papuã, apresentam potencial forrageiro. Restle et al. (2002), em estudo com papuã sob pastejo contínuo, de janeiro a abril, verificaram que o papuã apresentou excelente desempenho, com média de forragem de 2,79 t/ha de MS quando utilizada adubação de base de $300 \mathrm{~kg} / \mathrm{h}$ a da fórmula 05-30-15 e, em cobertura, $300 \mathrm{~kg} / \mathrm{ha}$ de nitrogênio. Trabalhando na mesma região com diferentes níveis de nitrogênio $(0,100$ e $200 \mathrm{~kg} / \mathrm{ha})$, Martins et al. (2000) obtiveram produções de MS de 4,6; 5,6 e $8,7 \mathrm{t} / \mathrm{ha}$, respectivamente, em pastagem de papuã. $\mathrm{O}$ aumento de material morto no decorrer dos pastejos, em ambos os sistemas, deve-se ao acúmulo de material senescente ao final de ciclo do azevém e das próprias espécies de ciclo estival que proporcionalmente apresentam quantidade maior de material morto em comparação às de ciclo hibernal. Essa assertiva é confirmada pela associação entre outras espécies e material morto $(0,4214 ; \mathrm{P}=0,490)$.

A carga animal (Tabela 1) não diferiu $(P>0,05)$ entre os sistemas forrageiros, tanto entre os pastejos quanto na média das avaliações. Nos períodos hibernal e estival, os valores médios foram de 2,22 e 2,29 e de 3,14 e 3,01 UA/ha, respectivamente, para os sistemas forrageiros $1 \mathrm{e} 2$. Valores inferiores ao deste trabalho foram encontrados por Sobczak et al. (2005) no Rio Grande do Sul com o mesmo cultivar. Esses autores avaliaram sistema forrageiro similar e obtiveram no período hibernal carga animal de 1,53 UA/ha. Carga média de 1,64 UA/ha foi obtida no período hibernal por Marchesan et al. (2002) em pastagem constituída por azevém, trevo-branco e cornichão com diversos níveis de adubação e utilizada por bovinos de corte. Valores semelhantes aos encontrados no período estival foram observados por Gonzales et al. (1996), que obtiveram carga de 2,9 UA/ha em capim-estrela-africana consorciado com amendoim forrageiro. Carga mais elevada, de 4,5 UA/ha, foi verificada por Deresz (2001a) em pastagem exclusiva de capim-elefante cv. Napier adubada com $200 \mathrm{~kg}$ de nitrogênio e potássio em 198 dias de avaliação com vacas em lactação.

\section{Conclusões}

A produção de forragem e a carga animal são semelhantes entre os sistemas forrageiros. A participação do azevém, das leguminosas e das espécies de crescimento espontâneo é importante para manter a oferta de forragem equilibrada, pois compensa o declínio natural na produção do capim-elefante. A presença de outras espécies nas entrelinhas do capim-elefante contribui para o aumento da massa de forragem da pastagem, mas prejudica o desempenho das leguminosas, que apresentam diferentes produções de forragem com ápices em períodos distintos.

\section{Literatura Citada}

ANDRADE, C.M.S.; VALENTIM, J.F. Adaptação e persistência de Arachis pintoi submetido a diferentes níveis de sombreamento. Revista Brasileira de Zootecnia, v.28, n.3, p.439-445, 1999

ANDRADE, C.M.S.; GARCIA, R.; VALENTIM, J.F. et al. Grazing management strategies for massaigrass-forage peanut pastures. 1. Dynamics of sward condition and botanical composition. Revista Brasileira de Zootecnia, v.35, n.2, p.334-342, 2006.

AROEIRA, L.J.M.; LOPES, F.C.F.; DERESZ, F. et al. Pasture availability and dry matter intake of lactating crossbred cows grazing elephantgrass (Pennisetum purpureum Schum). Animal Feed Science and Technology, v.78, n.3-4, p.313$324,1999$. 
ASSMANN, A.L.; PELISSARI, A.; MORAES, A. et al. Produção de gado de corte e acúmulo de matéria seca em sistema de integração lavoura-pecuária em presença e ausência de trevo-branco e nitrogênio. Revista Brasileira de Zootecnia, v.33, n.1, p.3744, 2004.

DALL'AGNOL, M.; SCHEFFER-BASSO, S.M.; NASCIMENTO, J.A.L. et al. Produção de forragem de capim-elefante sob clima frio. Curva de crescimento e valor nutritivo. Revista Brasileira de Zootecnia, v.33, n.5, p.1110-1117, 2004.

DERESZ, F. Influência do período de descanso da pastagem de capimelefante na produção de leite de vacas mestiças Holandês $x$ Zebu. Revista Brasileira de Zootecnia, v.30, n.2, p.461469, $2001 \mathrm{a}$.

DERESZ, F.; LOPES, F.C.F.; AROEIRA, L.J.M. Produção de leite de vacas mestiças holandês x zebu em pastagem de capimelefante, com e sem suplementação durante a época das chuvas. Arquivo Brasileiro de Medicina Veterinária e Zootecnia, v.55, n.3, p.334-340, 2001b.

EMPRESA BRASILEIRA DE PESQUISA E AGROPECUÁRIA EMBRAPA. Centro Nacional de Pesquisa de Solos. Sistema brasileiro de classificação de solos. Brasília: EMBRAPA, 1999. 412p

FARIA, V.P. Formas de uso do capim-elefante. In: PASSOS, L.P.; MARTINS, C.E.; BRESSAN, M. et al. (Eds.) Biologia e manejo do capim-elefante. Juiz de Fora: Embrapa Gado de Leite, 1999. p.119-130

FONSECA, D.M.; SALGADO, L.T.; QUEIROZ, D.S. et al. Produção de leite em pastagem de capim-elefante sob diferentes períodos de ocupação dos piquetes. Revista Brasileira de Zootecnia, v.27, n.5, p.848-856, 1998.

GONZALEZ, M.S.; NEURKVAN, L.M.; ROMERO, F. Produción de leche en pasturas de estrella africana (Cynodon nlemfuensis) solo y associado con Arachis pintoi o Desmodium ovalifolium. Pasturas Tropicales, v.18, n.1, p.2-12, 1996.

HILLESHEIM, A. Manejo do gênero Pennisetum sob pastejo. In: PEIXOTO, A.M.; MOURA, J.C.; FARIA, V.P. (Eds.) Plantas forrageiras de pastagens. Piracicaba: Fundação de Estudos Agrários Luiz de Queiroz, 1995. p.37-56.

LIMA, M.L.P.; BERCHIELLI, T.T.; LEME, P.R. et al. Concentração de nitrogênio uréico plasmático (NUP) e produção de leite de vacas mestiças mantidas em gramíneas tropicais sob pastejo rotacionado. Revista Brasileira de Zootecnia, v.33, n.6, p.1616-1626, 2004.

LOURENÇO, A.J.; SARTINI, H.J.; SANTAMARIA, M. Estudo comparativo entre três níveis de fertilização nitrogenada e consorciada com leguminosas em pastagens de capim-elefante napier (Pennisetum Purpureum Schum.) na determinação da capacidade de suporte. Boletim da Indústria Animal, v.35, n.1, p.69-80, 1987.

MARCHESAN, E.; VIZZOTTO, V.R.; ROCHA, M.G. et al. Produção animal em várzea sistematizada cultivada com forrageiras de estação fria submetidas a diferentes níveis de adubação. Ciência Rural, v.32, n.2, p.303-308, 2002.

MARTINS, J.D.; RESTLE, J.; BARRETO, I.L. Produção animal em capim-papuã (Brachiaria plantaginea (Link) Hitchc) submetido a níveis de nitrogênio. Ciência Rural, v.30, n.5, p.887-892, 2000.

MOREnO, J.A. Clima do Rio Grande do Sul. Porto Alegre: Secretaria da Agricultura, 1961. 41p.

OLIVO, C.J.; SOBCZAK, M.F.; CHARÃO, P.S. et al. [2006]. Avaliação de uma pastagem de capimelefante, manejada sob princípios agroecológicos, no período estival. Livestock Research for Rural Development, v.18, n.2, 2006. Disponível em: <http://www.cipav.org.co/lrrd/lrrd18/2/oliv18021.htm> Acesso em: 10/2/2006.

PAIM, N.R.; RIBOLDI, J. Duas novas cultivares de trevo branco comparadas com outras disponíveis no Rio Grande do Sul, em associação com gramíneas. Pesquisa Agropecuária Brasileira, v.29, n.1, p.43-53, 1994.

PEDREIRA, C.G.S.; ROSSETO, F.A.A.; SILVA, S.C. et al. Forage yield and grazing efficiency on rotationally stocked pastures of "tanzania-1" guineagrass and "guaçu" elephantgrass. Scientia Agricola, v.6, n.5, p.433-439, 2005.

PEREIRA, J.M. Produção e persistência de leguminosas em pastagens tropicais. In: SIMPÓSIO DE FORRAGICULTURA E PASTAGENS, 2., 2001, Lavras. Anais... Lavras: Universidade Federal de Lavras, 2001. p.111-142.

RESTLE, J.; ROSO, C.; AITA, V. et al. Produção animal em pastagem com gramíneas de estação quente. Revista Brasileira de Zootecnia, v.31, n.3, p.1491-1500, 2002 (supl.).

SANTANA, J.R.; PEREIRA, J.M.; RESENDE, C.P. Avaliação da consorciação de Brachiaria dictyoneura Stapf com Arachis pintoi Krapov. \& Gregory sob pastejo. In: REUNIÃO ANUAL DA SOCIEDADE BRASILEIRA DE ZOOTECNIA, 35., 1998, Botucatu. Anais... Botucatu: Sociedade Brasileira de Zootecnia, 1998. (CD-ROM).

SANTOS, I.P.A.; PINTO, J.C.; SIQUEIRA, J.O. et al. Influência do fósforo, micorriza e nitrogênio no conteúdo de minerais de Brachiaria brizanta e Arachis pintoi consorciados. Revista Brasileira de Zootecnia, v.31, n.2, p.605-616, 2002.

SANTOS, A.L.; LIMA, M.L.P.; BERCHIELLI, T.T. et al. Efeito do dia de ocupação sobre a produção leiteira de vacas mestiças em pastejo rotacionado de forrageiras tropicais. Revista Brasileira de Zootecnia, v.34, n.3, p.1051-1059, 2005.

SOCIEDADE BRASILEIRA DE CIÊNCIA DO SOLO - SBCS. Manual de adubação e calagem para os Estados do Rio Grande do Sul e Santa Catarina. Porto Alegre: 2004. 394p.

STATISTICAL ANALYSIS SYSTEM - SAS. User's guide: statistics. Version 6.11. Cary: SAS Institute, 1997. (CD-ROM).

SCHEFFER-BASSO, S.M.; JACQUES, A.V.; DALL' AGNOL, M. et al. Disponibilidade e valor nutritivo de forragem de leguminosas nativas (Adesmia DC.) e exóticas (Lotus L.). Revista Brasileira de Zootecnia, v.31, n.6, p.2197-2203, 2002.

SCHEFFER-BASSO, S.M.; VENDRUSCULO, M.C.; CECCHETTI, D. Desempenho de leguminosas nativas (Adesmia) e exóticas (Lotus, Trifolium), em função do estádio fenológico no primeiro corte. Revista Brasileira de Zootecnia, v.34, n.6, p.18711880, 2005.

SOARES, J.P.G.; BERCHIELLI, T.T.; AROEIRA, L.J.M. et al. Estimativas de consumo do capim-elefante (Pennisetum purpureum Schum.), fornecido picado para vacas lactantes utilizando a técnica do óxido crômico. Revista Brasileira de Zootecnia, v.33, n.3, p.811-820, 2004.

SOBCZAK, M.F.; OLIVO, C.J.; GABBI, A.M. et al. Evaluation of an elephantgrass pasture mixed with black oat managed under agroecological principles in winter period. Livestock Research for Rural Development, v.17, n.6, 2005. Disponível em: <http://www.cipav.org.co/lrrd/lrrd17/6/fati17071.htm> Acesso em: $10 / 02 / 2006$.

WILM, H.G.; COSTELLO, D.F.; KLIPPLE, G.E. Estimating forage yield by the double-sampling methods. Journal American Society Agronomy, v.36, p.194-203, 1944. 